\title{
ANALISIS EXPERIENTIAL MARKETING TERHADAP EXPERIENTIAL VALUE DI INDUSTRI SMARTPHONE
}

\author{
Rydho Styawan \\ Prodi Manajemen Fakultas Ekonomi Universitas Islam Indonesia \\ Budi Astuti \\ Prodi Manajemen Fakultas Ekonomi Universitas Islam Indonesia \\ twotiebudi@yahoo.com
}

\begin{abstract}
The stiff competition in the smartphone industry has forced the companies to embed the concept of experiential marketing and experiential value in positioning product to outdo their counterparts. Nowdays, the smartphone manufacturers are competing to offer their products and services for consumers based on the needs and desires development of consumers. Marketers are required to not just selling a product or service, but also to think how to create products and services that can provide a memorable experience for consumers. Research by the title of analysis of experiential marketing towards experiential value in the smartphone industry, is a replication of a research conducted by Maghnati, et al, entitled "Exploring the Relationship between Experiential Marketing and Experiential Value in the Smartphone Industry". The purpose of this research is to determine the effect of experiential marketing indicators such as sense experience, feel experience, act experience, relate experience, think experience on experiential value.This research was conducted by distributing questionnaires to survey the 500 students from 5 universities in Yogyakarta, which obtained through judgemental sampling and quota sampling methods. The result of Multiple Linear Regression Analysis with processing the data using software SPSS version 16 was: sense experience, feel experience, act experience, relate experience, think experience significant positive effect on experiential value. While the variables that have the most dominant influence in affecting the experiential value is variable think experience. The results concludes that this study supports the research of Maghnati. et al (2012) which found that experiential marketing is significant positive effect on experiential value.
\end{abstract}

Keywords: sense experience, feel experience, act experience, relate experience, think experience, experiential value

\begin{abstract}
Abstrak
Persaingan yang ketat di industri smartphone membuat perusahaan mulai menanamkan konsep experiential marketing dan experiential value dalam memposisikan produk untuk mengalahkan pesaing. Saat ini para produsen smartphone berlomba-lomba untuk menawarkan produk dan jasa bagi konsumen berdasarkan pada perkembangan kebutuhan dan keinginan konsumen. Produsen dituntut untuk tidak sekedar menjual produk atau jasa saja, tetapi juga berpikir bagaimana menciptakan produk maupun jasa yang dapat memberikan pengalaman berkesan bagi konsumennya. Penelitian dengan judul "Analisis Experiential Marketing terhadap Experiential Value di Industri Smartphone" ini merupakan replikasi penelitian yang dilakukan oleh Maghnati et al (2012), dengan judul "Exploring the Relationship between Experiential Marketing and Experiential Value in the Smartphone Industry". Penelitian ini bertujuan mengetahui pengaruh indikator experiential marketing yaitu sense experience, feel experience, act experience, relate experience, think experience terhadap experiential value. Jumlah sampel yang digunakan sebanyak 500 mahasiswa yang diperoleh melalui metode Judgement Sampling dan Quota Sampling yang diambil dari 5 perguruan tinggi di Daerah Istimewa Yogyakarta. Hasil dari Analisis Regresi Linear Berganda dengan pengolahan data menggunakan perangkat lunak SPSS versi 16: sense experience,
\end{abstract}


feel experience, act experience, relate experience, think experience berpengaruh positif signifikan terhadap experiential value. Variabel yang mempunyai pengaruh paling dominan dalam mempengaruhi experiential value adalah variable think experience. Dengan demikian hasil penelitian ini mendukung penelitian Maghnati. et al (2012) yang menemukan bahwa experiental marketing berpengaruh positif signifikan terhadap experiental value.

Kata kunci: Sense Experience, Feel Experience, Act Experience, Relate Experience, Think Experience, Experiential Value

\section{PENDAHULUAN}

Perkembangan zaman yang semakin maju mendorong teknologi informasi agar selalu berkembang dan saat ini teknologi informasi telah menciptakan regenerasi dari alat komunikasi yang super canggih, salah satunya adalah smartphone. Smartphone adalah telepon genggam yang super canggih dan fungsinya hampir menyerupai komputer. Smartphone yang memiliki konektivitas internet membuat seseorang dapat memperoleh informasi di belahan dunia hanya dalam hitungan detik.

Evolusi yang cepat dari pemasaran yang berfokus dari produk ke layanan dalam hal pengalaman telah menantang peneliti pemasaran melakukan pendekatan pengalaman pemasaran dalam merancang strategi pemasaran dengan melibatkan pelanggan (Maklan and Klaus, 2011). Indonesia merupakan negara pengguna smartphone dengan pengguna aktif sebanyak 47 juta, atau sekitar 14\% dari seluruh total pengguna ponsel dan jumlah ini diperkirakan akan terus berkembang khususnya di wilayah perkotaan. Pada tahun 2014 total smartphone yang terjual di tanah air mencapai 7,3 juta unit, atau dua per lima dari jumlah total penjualan di Asia Tenggara. Penjualan ini sebagian besar dikonstribusikan oleh mahasiswa Indonesia. Oleh karena itu sebagian besar produsen smartphone menanamkan konsep experiential marketing dan experiental value dalam memposisikan dan mempromosikan produk mereka agar mampu bersaing dengan pesaing lainnya.

Dengan demikian, kemampuan perusahaan untuk mempengaruhi experiental value pengguna smartphone ditentukan oleh strategi experiential marketing yang diciptakan oleh perusahaan. Oleh karena itu, penelitian ini bertujuan untuk meneliti pengaruh experiental marketing terhadap experiential value di antara para pengguna smartphone di Daerah Istimewa Yogyakarta.

\section{KAJIAN PUSTAKA}

\section{Experiential Value}

Menurut Lee dan Overby (2004), nilai bersifat subjektif dan dibuat berdasarkan pertukaran pengalaman yang terjadi dalam proses transaksi atau persepsi individu. Schroeder (2012) menyatakan bahwa pengalaman nyata dapat memudar tapi melupakan nilai pengalaman akan lebih sulit. Holbrook (2000) berpendapat bahwa pengalaman dalam mengkonsumsi memainkan peran penting dalam pengambilan keputusan pelanggan. Gentile et al. (2007) juga menyimpulkan hal yang sama dan menegaskan bahwa produk dan nilai-nilai pengalaman dapat dibuat melalui pengalaman mengkonsumsi. Experiential value diperoleh dari pengalaman, dan untuk itu experiential marketing yang baik akan menimbulkan experiential value yang dirasakan oleh pelanggan. Mathwick et al. (2001) telah mengembangkan tipologi nilai pengalaman yang termasuk ke dalam nilai-nilai aesthetic, playfulness, service excellence, dan consumer return on investment (CROI).

\section{Experiential Marketing}

Experiential marketing menurut Schmitt (1999) menyatakan bahwa pemasar menawarkan produk dan jasanya dengan merangsang unsurunsur emosi konsumen yang menghasilkan berbagai pengalaman bagi konsumen. Experiential marketing merupakan pemasaran berdasarkan apa yang dirasakan konsumen saat membeli barang dan jasa dari sebuah merek setelah mengalami berbagai aktivitas dan stimulasi (Schmitt, 1999). Lee et al. (2011) mendefinisikan experiential marketing sebagai ingatan yang mengesankan atau pengalaman yang terjadi kedalam pikiran pelanggan. Schmitt (1999) lebih lanjut menyatakan bahwa pengalaman ini meningkatkan nilai dari produk, merek, atau perusahaan. Schmitt (1999) membagi jenis experiential marketing menjadi 
lima dimensi: Sense Experience, Feel Experience, Think Experience, Act Experience dan Relate Experience.

\section{Sense Experience}

McCole (2004) menyatakan sense experience sebagai pengalaman yang didapatkan pelanggan dari pandangan mereka, rasa, aroma, sentuhan dan suara. Melalui sense experience, konsumen akan mampu mengembangkan pengalaman logika dan selanjutnya mereka menggunakan pengalaman logika untuk membentuk pribadi dalam mempertimbangkan membedakan produk dan layanan yang dialami oleh mereka atau fase pengalaman (pra pembelian, pembelian dan sesudah pembelian) (Vargo and Lusch, 2004). Chandra dan Subagio (2013) menemukan dimensi sense memiliki pengaruh secara dominan terhadap perceived value.

H1: Ada pengaruh positif signifikan antara sense experience dan experiential value pada pengguna smartphone.

\section{Feel Experience}

Feel experience disebut emosi, suasana hati dan perasaan pelanggan yang didapat dari mengkonsumsi produk dan jasa (Yang and $\mathrm{He}, 2011$; Yuan and $\mathrm{Wu}, 2008)$. Dengan perasaan positif yang dihasilkan dalam proses konsumsi, konsumen mengembangkan emosi positif (Schmitt, 1999). Menurut Mattila (2001), emosi yang kuat dan positif dalam pengalaman akan meningkatkan manajemen hubungan pelanggan antara pelanggan dan penjual. Badri dan Hartawan (2011) menunjukkan bahwa keterikatan secara emosional mempengaruhi dampak positif terhadap loyalitas konsumen.

$\mathrm{H} 2$ : Ada pengaruh positif signifikan antara feel experiential dan experiential value pada pengguna smartphone

\section{Think Experience}

Think experience menekankan pada kecerdasan konsumen dalam menghasilkan pengalaman kognitif (Lee et al., 2008). Menurut Schmitt (1999), Think experiential merangsang pemi kiran kreatif pelanggan dalam mengembangkan ide baru atau berpikir tentang sebuah perusahaan atau produknya. Tujuan think experience adalah mendorong konsumen sehingga tertarik dan berpikir secara kreatif sehingga mungkin dapat menghasilkan evaluasi kembali mengenai perusahaan dan merek tersebut (Januar dan Diah, 2013). Chih and Hung (2010) menemukan bahwa ketika wisatawan memiliki stimulus akal sehat, stimulus berpikir dan stimulus berhubungan maka kepuasan mereka akan naik.

H3: Ada pengaruh positif signifikan antara think experiential dan experiential value pada pengguna smartphone

\section{Act Experiential}

Menurut Schmit dalam Maghnati, et.al, (2012), act experiential memungkinkan konsumen untuk mengembangkan pengalaman yang berhubungan dengan tubuh fisik konsumen, perilaku dan gaya hidup serta pengalaman yang diperoleh dari interaksi sosial dengan orang lain. Di mana gaya hidup sendiri merupakan pola perilaku individu dalam hidup yang direfleksikan dalam tindakan, minat, dan pendapat. Tujuan dari act experience adalah untuk memberikan kesan terhadap pola perilaku dan gaya hidup, serta memperkaya pola interaksi sosial melalui strategi yang dilakukan (Januar dan Diah,2013). Melalui act experiential, konsumen mengembangkan rasa sensasi, pengaruh dan hubungan dengan produk atau jasa yang ditawarkan (Schimtt,1999). Maghnati, et.al, (2012) menyatakan act experiential berhubungan positif dengan experiental value di industri smartphone di Malaysia.

H4 : Ada pengaruh positif signifikan antara act experiential dan experiential value pada pengguna smartphone.

\section{Relate Experience}

Relate experience adalah salah satu cara membentuk atau menciptakan komunitas pelanggan dengan komunikasi (Kertajaya, 2004). Menceritakan pengalaman memungkinkan konsumen untuk membangun hubungan mereka dengan komunitas sosial melalui proses pembelian dan mengkonsumsi produk atau jasa (Chang et al., 2011). Dengan kata lain, relate experience yang dipromosikan melalui hubungan kampanye pemasaran memungkinkan konsumen untuk melakukan perbaikan diri, yang dipersepsi positif oleh orang lain dan menyatukan individu kedalam sebuah komuni- 
tas sosial (Schmitt, 1999). Tujuan dari relate experience adalah menghubungkan konsumen tersebut dengan budaya dan lingkungan sosial yang dicerminkan oleh merek suatu produk (Januar dan Diah, 2013). Ming, et.al (2010) menemukan relate experiential pada dimensi experiential marketing menyebabkan pengaruh yang lebih baik pada tenaga pelayanan dan nilai kepuasan pelanggan.

H5: Ada pengaruh positif signifikan antara relate experiential dan experiential value pada pengguna smartphone.

\section{METODE PENELITIAN}

Dalam penelitan ini populasinya adalah mahasiswa dari 5 Universitas berbeda di Daerah Istimewa Yogyakarta yang menggunakan smartphone atau bahkan yang pernah menggunakan smartphone. Sampel diperoleh menggunakan metode Judgement Sampling dan Quota Sampling. Metode pengumpulan data yang dilakukan oleh penulis yaitu dengan menggunakan kuesioner. Kuesioner disebarkan menggunakan dua metode, yaitu: penyebaran secara langsung dan penyebaran melalui online dengan menggunakan google docs. Responden dalam penelitian ini sebanyak 500 mahasiswa yang diambil dari 5 Universitas berbeda di Daerah Istimewa Yogyakarta.

Pertanyaan-pertanyaan yang digunakan untuk mengukur variabel yang ada di kuesioner diadopsi dari penelitian terdahulu yang releven, misalnya variabel-variabel experiential marketing dan variabel-variabel experiential value (Maghnati, et.al, 2012). Jawaban konsumen selanjutnya dianalisis dengan menggunakan skala Likert. Untuk setiap pertanyaan dalam penelitian ini disediakan 5 (lima) alternatif jawaban mulai dari "sangat tidak setuju" dengan skor 1, "tidak setuju" dengan skor 2, "cukup setuju" dengan skor 3, "setuju" dengan skor 4 dan "sangat setuju" dengan skor 5 . Untuk pengolahan data, peneliti menggunakan bantuan program komputer yaitu perangkat lunak SPSS versi 16.

Teknik analisis data yang digunakan dalam penelitian ini adalah Analisis Regresi Linear Berganda. Teknik analisis regresi berganda digunakan untuk mengetahui ada tidaknya pengaruh variabel experiential marketing secara bersama-sama terhadap variabel experiential value. Analisis regresi linear berganda ini digunakan untuk mengetahui seberapa besar pengaruh variabel independen: sense experience (X1), feel experience (X2), think experience (X3), act experience (X4), relate experience (X5) terhadap variabel dependen yaitu experiental value (Y) (Ghozali, 2005).

\section{HASIL ANALISIS}

\section{Hasil Uji Validitas dan Reliabilitas}

Hasil uji validitas data pada penelitian ini menunjukkan koefisien korelasi dari seluruh butir pertanyaan memiliki koefisien korelasi Product Moment Pearson (rxy) $>\mathrm{r}_{\text {tabel }}(0,306)$. Dengan demikian seluruh butir pertanyaan yang ada pada instrument penelitian dapat dinyatakan valid atau sahih. Sedangkan untuk uji reliabilitas data diketahui nilai koefisien Cronbach Alpha pada masing-masing variabel nilainya lebih besar dari 0,6 , maka semua butir pertanyaan dalam variabel penelitian adalah reliable, sehingga instrumen penelitian ini dalam pengukurannya dapat dipercaya.

\section{Hasil Uji Asumsi Klasik}

Sebelum dilakukan analisis regresi linear berganda terlebih dahulu dilakukan uji asumsi klasik, yang bertujuan agar model regresi yang dilakukan dalam penelitian ini tidak menghasilkan kesimpulan bias. Adapun uji asumsi klasik yang dilakukan adalah:

\section{Uji normalitas}

Hasil uji normalitas pada penelitian ini ditemukan bahwa sebaran data menyebar disekitar garis diagonal dan mengikuti arah garis diagonal, maka dapat disimpulkan bahwa model regresi linear berdistribusi normal.

\section{Uji multikolinearitas}

Dalam penelitian ini hasil dari Uji Multikolinearitas diketahui bahwa seluruh variabel independen yang terdiri dari sense experience, feel experience, think experience, act experience, dan relate experience memiliki nilai VIF kurang dari 10. Dengan demikian model regresi yang digunakan dalam penelitian ini tidak mengandung gejala multikonieritas.

\section{Uji heteroskedastisitas}

Hasil pengujian heteroskedastisitas dalam penelitian ini ditemukan data residual pada 
model pertama regresi menyebar baik diatas maupun dibawah titik 0 dan tidak membentuk pola tertentu. Dengan demikian model regresi yang diajukan dalam penelitian ini tidak terjadi gejala Heteroskedastisitas.

\section{Hasil Analisis Regresi Linear Berganda}

Analisis Regresi Linear Berganda digunakan karena variable bebas dalam penelitian ini lebih dari satu yaitu 5 dimensi experiential marketing. Dalam penelitian ini, penulis menganalisis regresi linear berganda menggunakan program statistik SPSS versi16. Hasil dari analisis regresi linear berganda ditunjukkan pada Tabel 1 .

Berdasarkan hasil analisis regresi linear berganda pada Tabel 1, dapat dibuat persamaan regresi sebagai berikut:

$$
\begin{aligned}
\mathrm{Y}= & 0,055+0,216 \mathrm{X}_{1}+0,217 \mathrm{X}_{2}+0,225 \mathrm{X}_{3}+ \\
& 0,209 \mathrm{X}_{4}+0,107 \mathrm{X}_{5}
\end{aligned}
$$

\section{Hasil Uji Hipotesis}

\section{Hasil uji F}

Hasil uji F seperti tampak pada Tabel1 diketahui $\mathrm{F}_{\text {hitung }} 71.722>\mathrm{F}_{\text {tabel }} 2,23$ dan nilai signifikansi $0,00<0,05$. Sehingga dapat disimpulkan bahwa $\mathrm{H}_{0}$ ditolak dan $\mathrm{H}_{\mathrm{a}}$ diterima. Dengan demikian Ho ditolak dan Ha diterima yang berarti ada pengaruh secara serentak dan signifikan variabel experiential marketing yang terdiri dari dimensi sense experience, feel experience, think experience, act experience, dan relate experience terhadap experiential value.

\section{Hasil uji t}

Hasil uji $t$ seperti tampak pada Tabel 1 menunjukkan nilai signifikasi dari variabel exeperiential marketing yaitu sense experience, feel experience, think experience, act experience dan relate experience $<0,05$. Hal ini berarti Ho ditolak yang berarti terdapat pengaruh secara parsial dan signifikan dimensi variabel experiential marketing terhadap experiential value.

\section{Hasil uji $\mathbf{R}^{2}$}

Pada Tabel1 menunjukkan besarnya koefisien determinasi $\left(R^{2}\right)=0,421$ atau dengan kata lain sebesar $42,1 \%$ yang menunjukkan variabel experiential value dapat dijelaskan oleh kelima variabel yaitu sense experience, feel experience, think experience, act experience, dan relate experience. Sedangkan sisanya sebesar $58,9 \%$ dipengaruhi oleh variabel lain yang tidak dimasukkan dalam model penelitian.

\begin{tabular}{|c|c|c|c|c|c|c|}
\hline \multirow[b]{2}{*}{ Variabel Independen } & \multicolumn{2}{|c|}{$\begin{array}{l}\text { Regresion } \\
\text { Coefficient }\end{array}$} & \multicolumn{2}{|c|}{ Uji $t$} & \multicolumn{2}{|c|}{$\begin{array}{c}\text { Determinasi } \\
\text { Partial } \\
\end{array}$} \\
\hline & $\mathrm{B}$ & Beta & $\mathrm{T}$ & sig & $\mathrm{r}$ & $r^{2}$ \\
\hline Konstanta & 0.055 & & 0.272 & 0.786 & & \\
\hline Sense Experience & 0.216 & 0.210 & 5.746 & 0.000 & 0.250 & 0.063 \\
\hline Feel Experience & 0.217 & 0.231 & 5.732 & 0.000 & 0.250 & 0.062 \\
\hline Think Experience & 0.225 & 0.231 & 5.908 & 0.000 & 0.257 & 0.066 \\
\hline Act Experience & 0.209 & 0.218 & 5.680 & 0.000 & 0.248 & 0.061 \\
\hline Relate Experience & 0.107 & 0.116 & 3.262 & 0.001 & 0.145 & 0.021 \\
\hline$R$ & 0.649 & & & & & \\
\hline$R^{2}$ & 0.421 & & & & & \\
\hline F test & 71.722 & & & & & \\
\hline Sig $F$ & 0.000 & & & & & \\
\hline
\end{tabular}

Tabel 1: Hasil Analisis Regresi Linear Berganda

Sumber:Data primer yang diolah, 2015 


\section{PEMBAHASAN}

Hasil dari penelitian ini menunjukkan adanya pengaruh yang positif dan signifikan antara variabel experiential marketing yaitu sense experience, feel experience, think experience, act experience, dan relate experience terhadap experiential value. Selanjutnya akan dibahas sebagai berikut:

\section{Pengaruh sense experience terhadap experiential value}

Hasil penelitian menunjukkan adanya pengaruh positif dan signifikan antara variabel sense experience terhadap experiential value pada pengguna smartphone. Dengan demikian hasil penelitian ini mendukung penelitian sebelumnya yang dilakukan oleh Maghnati et.al (2012) yang menemukan bahwa sense experience berpengaruh positif dan signifikan terhadap experiential value dalam industri smartphone. Indikator yang dinilai paling rendah oleh konsumen dalam penelitian ini adalah fitur produk smartphone konsumen sangat istimewa. Dengan demikian produsen smartphone diharapkan dapat meningkatkan fitur-fitur smartphone seperti, layar dan kamera yang jernih, ruang penyimpanan data (RAM) yang besar, memiliki pemindai sidik jari dan fitur-fitur lainnya.

\section{Pengaruh feel experience terhadap experiential value}

Penelitian yang dilakukan oleh Maghnati et al (2012) menemukan, feel experience berpengaruh positif dan signifikan terhadap experiential value dalam industri smartphone. Hal ini sesuai dengan penelitian ini, dimana menunjukkan adanya pengaruh positif dan signifikan antara variabel feel experience terhadap experiential value pada pengguna smartphone. Item pertanyaan menggunakan smartphone membuat saya merasa nyaman memiliki nilai rata-rata terendah. Dengan demikian produsen smartphone diharapkan dapat meningkatkan rasa kenyamanan pada konsumen misalnya dengan memberikan informasi yang jelas dan lengkap mengenai penggunaan fitur-fitur yang ada pada sistem operasi smartphone.

\section{Pengaruh Think Experience terhadap Experiential Value}

Variabel think experience memiliki pengaruh positif dan signifikan terhadap variabel expe- riential value pada pengguna smartphone dalam penelitian ini. Hasil penelitian ini mendukung penelitian sebelumnya yang dilakukan Chih dan Hung, (2010) dan penelitian Maghnati, et al (2012), dimana studi ini menemukan bahwa think experience berpengaruh positif signifikan terhadap experiential value. Hasil penelitian menemukan item yang dinilai paling rendah oleh responden adalah aktivitas pengalaman yang khas pada saat menggunakan smartphone. Hal ini disebabkan karena fitur produk smartphone yang terdapat dalam sistem operasinya tidak dapat memikat konsumen dalam hal ini responden. Dengan demikian produsen smartphone diharapkan dapat memberikan atau menyediakan fitur-fitur yang bermanfaat dan memberikan kemudahan dalam aktivitas konsumen dalam menggunakan smartphone, hal ini dapat diwujudkan dengan melakukan R\&D pada konsumen pengguna smartphone.

\section{Pengaruh act experience terhadap experiential value}

Hasil penelitian ini menemukan adanya pengaruh positif dan signifikan antara variabel act experience terhadap experiential value pada pengguna smartphone. Hasil penelitian ini mendukung penelitian sebelumnya yang dilakukan Maghnati, et al (2012) yang menyatakan act experience berpengaruh positif dan signifikan terhadap experiential value. Item pertanyaan yang dinilai paling rendah oleh responden adalah setiap indikasi pada smartphone memudahkan saya untuk memahami fitur-fitur unik dari smartphone tersebut. Hal ini dikarenakan responden tidak memiliki aktivitas dan pengalaman dalam menggunakan fitur-fitur unik yang tersedia pada smartphone responden. Dengan demikian produsen smartphone diharapkan dapat terus menerus melakukan kajian ulang, penyesuaian dan mentransformasikan dimensi-dimensi perubahan untuk mendorong penciptaan nilai (memotivasi, menginspirasi, dan spontan) yang terukur terhadap setiap keunikan fitur-fitur pada smartphone yang sesuai dengan gaya hidup konsumen

\section{Pengaruh Relate Experience terhadap Experiential Value}

Penelitian yang dilakukan Maghnati et.al (2012) dan Ming, et.al (2010) menemukan 
bahwa relate experience berpengaruh positif dan signifikan terhadap experiential value. Hal ini mendukung hasil penelitian ini dimana, menunjukkan adanya pengaruh positif dan signifikan antara variabel relate experience terhadap experiential value pada pengguna smartphone. Nilai rata-rata terendah pada item variabel dalam penelitian ini yaitu fitur-fitur smartphone membuat saya berpikir tentang pentingnya memiliki fungsi-fungsi smartphone. Hal ini dikarenakan budaya penggunaan smartphone yang terbentuk pada responden oleh kelompok referensi lebih menekankan pada fungsi gaya hidup dibandingkan fungsi sebenarnya dari fungsi smartphone tersebut. Dengan demikian produsen smartphone diharapkan dapat menaruh perhatian dengan melakukan R\&D kepada kelompok-kelompok referensi yang dapat mempengaruhi individu atau konsumen agar lebih mudah memahami apa yang diinginkan konsumen, sehingga produsen smartphone dapat menyediakan fiturfitur yang mendukung setiap fungsi penggunaan smartphone oleh konsumen atau membentuk suatu referensi mengenai fungsi sebenarnya dari fitur-fitur smartphone kepada pengguna smartphone.

\section{PENUTUP}

\section{Kesimpulan}

Penelitian ini bertujuan untuk menguji pengaruh variabel experiential marketing yaitu sense experience, feel experience, think experience, act experience dan relate experience terhadap experiential value pada pengguna smartphone. Dari hasil analisis yang telah dilakukan atas dasar hasil pengolahan data penelitian, dapat ditarik kesimpulan sebagai berikut: 1) Sense experience terbukti berpengaruh positif signifikan terhadap experiential value pada pengguna smartphone. Hal ini berarti semakin baik experiential marketing pada sense experience maka experiential value akan semakin meningkat. 2) Feel experience terbukti berpengaruh positif signifikan terhadap experiential value pada pengguna smartphone. Hal ini berarti semakin baik experiential marketing pada feel experience maka experiential value akan semakin meningkat. 3) Think experience terbukti berpengaruh positif signifikan terhadap experiential value pada pengguna smartphone. Hal ini berarti semakin baik experiential marketing pada think experience maka experiential value akan semakin meningkat. 4) Act experience terbukti berpengaruh positif signifikan terhadap experiential value pada pengguna smartphone. Hal ini berarti semakin baik experiential marketing pada act experience maka experiential value akan semakin meningkat. 5) Relate experience terbukti berpengaruh positif signifikan terhadap experiential value pada pengguna smartphone. Hal ini berarti semakin baik experiential marketing pada relate experience maka experiential value akan semakin meningkat.

\section{Saran}

Hasil penelitian menunjukan bahwa, dari kelima variabel independen experiential marketing yaitu sense experience, feel experience, think experience, act experience dan relate experience, variabel think experience memiliki pengaruh paling besar diantara variabel lainnya, namun demikian persepsi responden terhadap variabel ini sangat kecil dibandingkan variabel lainnya terhadap variabel experiential value yang merupakan persepsi individu berdasarkan pertukaran pengalaman. Hal ini tentunya menggambarkan bagaimana perhatian perusahaan terhadap think experience konsumen atau kecerdasan konsumen masih sangat rendah. Dengan demikian perusahaan diharapkan mampu menentukan segmentasi pasar smartphone sehingga mampu menciptakan dan mengembangkan fitur-fitur yang ada pasa smartphone sesuai dengan think experience yang dimiliki oleh konsumen atau segmen yang ditargetkan.

Hasil penelitian ini tentunya sangat terbatas, sehingga diharapkan kedepannya penelitian selanjutnya dapat melengkapi dan mengembangkan penelitian ini baik secara pengembangan variabel penelitian maupun populasi dan sampel penelitian. Penelitian selanjutnya juga dapat mengembangkan penelitian ini berdasarkan sudut pandang gender dimana pada hasil penelitian ini telah menunjukan bahwa sebagian besar pengguna smartphone adalah perempuan.

\section{DAFTAR PUSTAKA}

Badri, M. S. dan R. A. Hartawan. 2011. Pengaruh Pengalaman dan Keterikatan Emosional pada Merk terhadap Loyalitas 
Konsumen, Jurnal Manajemen Teori dan Terapan. 4 (3), pp:1 12

Chandra, I dan Hartono, S. 2013. Analisa Pengaruh Experiential Marketing Terhadap Customer Satisfaction Dengan Perceived Value Sebagai Variabel Intervening Konsumen the Premiere Grand City Surabaya. Jurnal Manajemen Pemasaran Petra. Vol. 1 No. 2, pp: $1-10$.

Chih, Y. W., C. Hung Lin. 2010. A Study of the Effect of TV Drama on Relationships among Tourists' Experiential Marketing, Experiential Value and Satisfaction. International Journal of Organizational Innovation.

Gentile, C., Spiller, N., and Noci, G. 2007. How to Sustain the Customer Experience: An Overview of Experience Components that Co-create Value with the Customer. European Management Journal, 25(5), 395-410.

Ghozali, Imam. 2005. Analisis Multivariat dengan Program SPSS. Edisi ke-3. Badan Penerbit UNDIP. Semarang.

Holbrook, M. B. 2000. The Millennial Consumer in the Texts of Our Times: Experience and Entertainment. Journal of Macro marketing, 20(2), 178-192.

Januar,T.O dan Diah, D. 2013. Analisa Pengaruh Experiental Marketing Terhadap Loyalitas Konsumen Melalui Kepuasan Sebagai Intervening Variabel di Tator Cafe Surabaya Town Square. Jurnal Manajemen Pemasaran, Vol 1, No 2, $1-9$

Kertajaya, Hermawan. 2004. Marketing In Venus. Jakarta : Gramedia.

Lee, E. J., and Overby, J. W. (2004).Creating Value for Online Shoppers: Implications for Satisfaction and Loyalty. Journal of Consumer Satisfaction, Dissatisfaction and Complaining Behavior, 17, 54-67.

Lee, M. S., Hsiao, H. D., and Yang, M. F. 2011. The Study of the Relationships among Experiential Marketing, Service Quality, Customer Satisfaction and
Customer Loyalty. The International Journal of Organizational Innovation, 3(2), 353-379.

Lee, S. H., Chang, S. C., and Hou, J. S. 2008. Night Market Experience and Image. International Journal of Culture, Tourism and Hospitality Research, 2(3), 217-233.

Maghnati, F., and K. C. Ling. 2013. Exploring the Relationship between Experiential Value and Usage Attitude towards Mobile Apps among the Smartphone Users. International Journal of Business and Management; Vol. 8.

Maghnati, F., K. C. ling and A. Nasermoadeli. 2012. Exploring the Relationship between Experiential Marketing and Experiential Value in the Smartphone Industry. International Business Research. 5 (11), pp:169-177.

Maklan, S., and Klaus, P. 2011. Customer Experience: Are We Measuring the Right Things?. International Journal of Market Research, 53(6).

Mattila, A. S. 2001. Emotional Bonding and Restaurant Loyalty. Cornell Hotel and Restaurant Administration Quarterly, 42(6), 73-79.

McCole, P. 2004. Refocusing Marketing to Reflect Practice the Changing Role of Marketing for Business. Marketing Intelligence \& Planning, 22(5), 531539.

Ming, S. L., H. Der Hsiao and M. Fen Yang. 2010. The Study of the Relationships among Experiential Marketing, Service quality, Coustomer Satisfaction and Coustomer Loyalty. International Jurnal of Organizational Innovation(online) 3 (2), pp: 352-378.

Schmitt, B. H. 1999. Experiential Marketing. Journal of Marketing Management, 15(1), 53-67.

Schroeder, H. W. 2012. Giving Voice to the Experiential Value of Natural Environments. The Humanistic Psychologist, 40(2), 136-152. 
Vargo, S. L., and Lusch, R. F. 2004. Evaluating to a new dominant logic for marketing. Journal of Marketing, 68(1), 1-17.

Yang, Z. Y., and He, L. Y. 2011. Goal, Customer Experience and Purchase
Intention in a Retail Context in China: An empirical study. African Journal of Business Management, 5(16), 67386746. 